Without imagining that my opinions will be preferred to those of other writers, I yet think that a rather extensive experience may be my apology for suggesting that, instead of injecting iron, iced water, or chloralum, placing the child to the breasts, compressing the aorta, using galvanism, special " binders," or transfusion (to prepare or employ either of which mode of treatment involves necessarily more than the few minutes required for the death of the patient in such cases), the use of remedies sure to be at hand should be preferred, of which brandy, in my view, is the chief.

It was taught by an eminent physician many years ago in his lectures, that, if death resulted from hæmorrhage, while a supply of brandy was at hand, the fault was attributable to the medical attendant : a bold assertion to make, no doubt, but nevertheless a true one. In such cases all the remedies wanted are brandy and ergot, and in addition, if possible, ice. The administration of brandy is too lightly thought of -it is mentioned by some recent writers in the JOURNAL, but not as the chief remedy. It may be given to any extent required, the pulse alone being the indi. cator as to quantity, mixed with equal parts of water, and poured down at short intervals, should the flagging heart require it. The stomach will reject it, almost as a rule, the moment vitality is restored; and if it be retained, which it sometimes but very rarely is, no harm will come of it. If the left hand grasp the uterus through the abdomen so firmly that it cannot dilate, while the right removes the placenta, as well as all coagula that may form in the uterus, and, if there be ice, carries portions of it within the cavity, no other remedies will be wanted. As vitality is restored, the uterus contracts, and all danger is over: then is the time to give nourishment. Free air should be admitted by open windows, and from the moment uterine contraction is established, the warmth of the body should be promoted.

It has always seemed to me that the use of abdominal bandages is but little understood as a remedy ; no bandage can be so firmly placed as to prevent the dilatation of the uterus, while the hand firmly fixed on it can grasp it with such power that dilatation and relaxation are impossible; and, until contraction has been complete for at least half-an-hour, the hand should not be removed. By the hand is learnt the condition of the uterus also; and the occurrence of what is called secondary hæmorrhage is entirely due to too much faith being placed in bandages, under which the uterus will be filling with blood unobserved, until the occurrence of alarming syncope.

The injection of perchloride of iron is not likely to become a popular remedy. It is known to produce mischief, which I myself have witnessed, and even death; and besides, it is never required. I have also witnessed the fatal effects of injection of iced water, as well as its inefficiency in checking uterine hæmorrhage. It was injected by a very able medical man before my arrival, in a case to which $\mathbf{I}$ was called; the patient complained of intense coldness over the whole abdomen, accompanied by pain. She was not faint, but she died as those die who have received peritoneal injury. It was the opinion of both the medical attendant and myself, that solid ice introduced into the uterus was preferable to iced water injection, for we were both impressed with the conviction that the iced water had here reached the peritoneum through the Fallopian tubes.

To prevent post partum hæmorrhage, does not require quite the same energy as to control it when it occurs. Time is not so pressing. When women have once flooded, they are liable to do so again; the general health of such women should be attended to during pregnancy; tone should be given to the abdominal muscles especially; the remedies, however, must be adapted to the patient's condition. When labour begins, the pulse should be well sustained by nourishment and stimulants, brandy in fair quantities being given. The use of ergot as a preventative is most important; the writers in the JOURNAL allude to its use, but they differ as to the dose, and as to the time of giving it. The effect of ergot is certainly not apparent under twenty minutes; hence I am not disposed to think it useful when given at the moment of the expulsion of the foetus. As nearly as possible, it should be given twenty minutes, therefore, before the birth, and I have never found the effect produced by any less dose than sixty minims. It never injures the child when administered judiciously ; but the dose should be, under any circumstances, not less than sixty minims of the fluid extract of the Pharmacopocia.

The labour should not be hurried, and it is as well to avoid giving ergot during its progress, except the single dose mentioned. As the foetus is expelled, the left hand, as suggested by more than one of the recent writers, should firmly press the uterus downwards, following it so that it still receives the pressure, not only after the birth is accomplished, but until after the placenta has also been expelled. No doub the presence of the placenta, whether wholly or partially detached, excites bleeding; hence there should be no great delay in its being removed, but no forcible extraction should be adopted. My own expe- rience goes to prove that this mode of treatment will always be successful, and that there will be no need, if it is adopted, of the anticipation of the necessity for transfusion as suggested by one of the correspondents of the JOURNAL.

The is still another form of hremorrhage not noticed in these com muinications. I allude to bleeding during pregnancy, and especially after the seventh month, or at the fall term of gestation, before labour has commenced. There is no condition requiring more judicious management than this contingency at the latter months, and none so likely to be fatal unless properly treated. Perhaps others, who have not written, will record their views on this subject on some future occasion; and, if this be done with the same ability with which they have written upon the other forms of hæmorrhage, their suggestions will be productive of the greatest good.

\section{THE DEPRESSANTS OF THE CIRCULATION AND} THEIR USE.*

\section{By J. MILNER FOTHERGILL, M.D., M.R.C.P.,}

[Concluded from p. 47 of last number.]

NITRITE of amyl is an agent which produces, when inhaled, a distinct and remarkable blushing, obviously from its dilating the minute peripheral vessels. Some years ago, Dr. Lauder Brunton found that, in a case of angina pectoris which came under his notice, there was a decided increase of arterial tension in the attack ; and this he attributed to peripheral spasm. He reasoned, and rightly too, that nitrite of amyl ongit to relieve this condition, and the practical outcome of this application of physiological knowledge was the relief of the patient. A more perfect demonstration of the power of physiological research to aid practical medicine is not necessary to disprove a charge often pressed. More recently, Dr. Crichton Browne used amyl as a test of the vasomotor mobility of epileptics, and has found them extremely susceptible to its action. He tried it in the treatment of the fit, however, without success. Observing that there is a rise in the arterial tension at the instant of the oncome of the fit, he tried inhalations of the amyl just before the oncome of rhythmically recurring fits with the following result.

E. W., aged 27, had, from January Ist to March 26th (eighty-five days), no less than eighty fits, usually daily, and during March, one each day. On March 27th, amyl inhalations were commenced. The fits were immediately and abruptly discontinued; and there was no recurrence of them till April 15 th. The fits have returned, but unfrequently, though the inhalations had been almost abandoned (West Riding Lunatic Asylum Reports, vol. iii).

In Dr. Ferrier's experiments as to the localisation of the functions of the brain, commenced at Wakefield Asylum last Easter, it was very pretty, as well as instructive, to see how the inhalation of amyl previously to the application of the electrodes to the entire cerebral hemisphere on one side, arrested the unilateral fit which would have been, and was otherwise, produced.

Further experience of nitrite of amyl at Wakefield is accumulating testimony as to its power over recurrent epilepsy, and in averting that miserable condition which is the consequence of recurrent fits, called the status epilepticus.

There seems every reason to believe, though as yet it is not possible to be more certain, that in inhalations of nitrite of amyl will be found the most efficient, as well as agreeable method of treating attacks of hysteria, where there is spasm of the arterioles.

Nitrite of amyl will probably also be found useful in the treatment of chronic Bright's disease when the tension is high, the pulse corded, the action of the heart violent, often amounting to palpitation, the flow of limpid urine profuse, and the sleeplessness and mental irritability pronounced. Dr. Balthazar Foster is kindly testing the amyl in these conditions for me; but his results have not yet come to hand. One interesting case, illustrating well the action of amyl, he has already furnished to me. He says: "I used it in some heart-cases. In one especially it did well-a case of aortic insufficiency-with great hypertrophic compensation. In this case, there were great frontal headache and very violent heart-action, associated with high arterial tension. The nitrite of amyl relieved these conditions like magic."

Dr. Brunton has kindly placed at my disposal three sphygmographic tracings of the pulse in angina before and after the inhalation of amyl. The first figure gives the pulse in its normal condition, as seen before the attack came on, and after the attack had entirely passed off. (Fig.

* Read before the Medical Society of London. 
I.) He says : "During the attack of angina, the capillaries became contracted, and the arterial tension rose, as seen in Fig. 2. When the

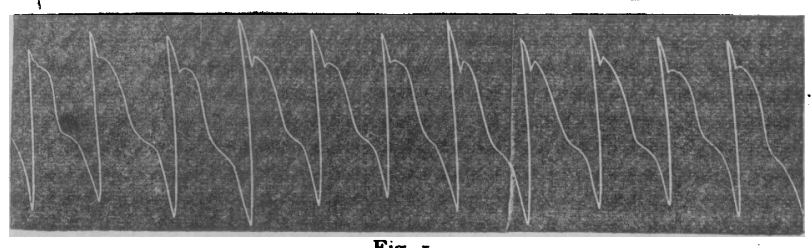

Fig. $x$.

nitrite was inhaled, the pulse in most cases quickly regained its normal character; but, when the pain remained in the region of the nipple after the inhalation, the arterial tension fell as usual, indicating

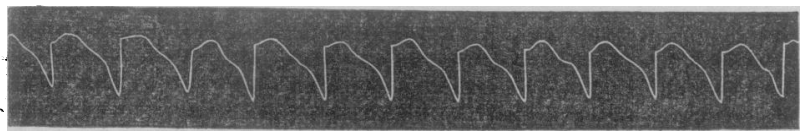

Fig. 2.

dilatation of the systemic capillaries; but the volume of the pulse remained small, as shown in Fig. 3." (On the Employment of Nitrite of Amyl in the Collapse of Cholera, BRrr. MrD. Jour., Jan. 13, 1872.)

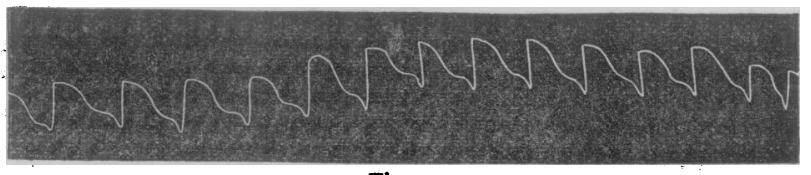

Fig. 3.

Calabar bean is a new therapeutic agent, for whose introduction into practical medicine we are indebted to physiological inquiry. It has been found to exercise a very beneficial effect over the course of that terrible malady, the general paralysis of the insane; and its use for such purpose took its origin in the perusal by Dr. Crichton Browne of Wakefeld of a paper on the Calabar Bean by Dr. Fraser of Edinburgh, in the Transactions of the Royal Society of Edinburgh for 1867 . Dr. Fraser described motor paralysis as one of the actions of the bean in full doses ; and Dr. Browne conceived the idea of utilising this action to control the violence of the muscular movements of these patients in their periodical outbreaks of excitement. It was found to be most useful for this purpose ; but something further was observed. Its use was found to exercise a beneficial influence over the progress of these unhappy cases; so much so that, in many cases, the untoward movement was arrested. After careful examination of numerous cases, it appeared to me that this beneficial action was due, to a great extent at least, to the effect of the physostigma upon the heart. Dr. Fraser found that the action of the bean was to diminish the vitality of the cardiac ganglia. With small doses, the heart's beats were diminished in frequency; and with larger doses, death arose from cardiac syncope. Though not quite agreeing with those of Von Bezold and Götz, Dr. Fraser's experiments are such as to inspire every confidence; and he found that the heart remained permanently in diastole and full of dark blood. In general paralysis of the insane, there is usually, in the earlier stages, high arterial tension, a powerful heart with much ac. centuation of the aortic second sound, cerebral hyperæmia, with grandiose delusions and periodical fits of general excitement.* That Calabar bean should exert a beneficial action upon such cases, is only what we might $d$ priori expect from its physiological action; and, in actual fact, Dr. Browne has discharged a number of patients this year with their disease arrested. Dr. Fraser found that the bean dilated the peripheral vessels, as well as markedly depressing the heart's action; and the combined effect is to lower the blood-pressure on the brain, and so relieve the cerebral hyperæmia which is associated with this form of insanity. It may possess some action upon the motor centres other than that exercised by its effect upon the circulation, but of this there is no proof as yet; and its action upon the vascular system is, in all probability, the explanation of its beneficial action in these cases.

Dr. Browne has kindly supplied me with two illustrative cases of general paralysis successfully treated by the administration of Calabar bean, which I propose to read to you. $t$

* See a paper on the Heart-Sounds in General Paralysis of the Insane (West Riding Lunatic Asylum Reports, vol. iii, 1873 ).

t The complete Asylum Reports, vol. iii, r873). Browne. Abstracts of them will be found in the report of the proceedings of the Medical Society of London, at page 60 of last number.
Dr. Forbes, of Shoreditch Infirmary, has also tried Calabar bean in the treatment of acute cerebral conditions. He writes to me to the following effect. "I have not yet been able to give the 'bean' a suff. cient trial ; but, from what little I have seen of it, I am of opinion that it is a very useful remedy in the first stage of acute mania."

It would appear that the effect of the Calabar bean upon the cardiac ganglia is not only to depress their activity, but also to render them much more susceptible to extrinsic impressions. Thus, the exertion of walking, and the increased demand made upon the heart by this effort, will often produce temporary cardiac syncope ; and, on several occasions, patients at Wakefield have been attacked by faintness when on their daily walk, while under the influence of the Calabar bean. No serious consequences, however, have resulted from its use, and the fainting soon passes away. But 'these easily induced syncopal attacks tell us how powerfully the physostigma acts upon the cardiac ganglia. The use of Calabar bean in the treatment of conditions of active hyperæmia within the encephalon, will probably ere long be general; and the application of cardiac depressants to the relief of cerebral hypervascularity, be another proof of the aid which physiology can afford to practical medicine. (Fournal of Mental Science, April 1871, p. 149.)

Dangerous depression of the heart's action has always been the drawback to the use of these depressant agents, and has frequently occurred from the ordinary doses of antimony in common use. Whether idiosyncrasy extends so powerfully to the vegetable depressants or not, we cannot feel positive; but the Calabar bean fainting at Wakefield has so far been free from unpleasant consequences. It will be encouraging to those who propose to use aconite or Calabar bean in their practice, to know that both these agents have powerful antidotes, in case any symptoms provoking anxiety should arise. Fraser has gone at great length into the antagonism which exists betwixt the physostigma and belladonna; and Kleinwachter found physostigma exercised a marked influence over a case of belladonna poisoning. As to aconite, I myself found that in the frog, digitalis was a perfect antidote; and, soon after this observation, an opportunity of testing this in the human subject offered itself to my friend Mr. Dobie of Keighley. A veterinary surgeon of that town swallowed a large quantity of the tincture of aconite, and was apparently moribund, in spite of all the usual remedial measures. Mr. Dobie, being acquainted with my experiments, tried the antidotal action of digitalis, first administering it subcutaneously, and afterwards, as the man recovered a little, by the mouth. Complete recovery followed; and, from the history of the case, it is impossible to avoid the conclusion that the digitalis was largely instrumental in the induction of. this result. The case is recorded in the BRITISH MEDICAL Journal of December 21 st, 1872 .

Veratrum viride has long enjoyed a reputation, chiefly in America, as a neurotic of the circulation. Bullock has recently obtained from it two alkaloids, which he has named viridia and veratroidia; and Horatio Wood has investigated the action of each. Viridia, he says, is " a direct depressant of the circulation, lowering the force and rapidity of the blood-streams, slowing the action of the heart, and finally affecting the force of the single beat, independently of any spinal action it may assert. Veratroidia also depresses the heart's action, both in force and frequency, but the period of depression is followed by one of reaction." (American Fournal of Medical Sciences, lix, p. 36.) Veratrum has also been tried on that curious therapeutic touchstonepneumonia, and been pronounced to be of value, especially in sthenic cases.

Veratrum, aconite, and morphia, by subcutaneous injection, have all proved useful in the treatment of palpitation. Except in anæmic cases, palpitation is an active sign of incapacity, of inability upon the part of the heart to perform its duties smoothly, and indicates obvious effort; consequently, it is not likely to be benefited by a depressant in any other way than you can quiet a struggling creature by knocking it senseless or powerless, but this can scarcely be regarded as improving it much. Still, many cases of palpitation are unquestionably improved by the administration of these remedies; but these are cases not of incapacity or debility in the heart itself, but rather of increased obstruction offered to the blood-flow by spasm of the arterioles; the contracted peripheral vessels increasing the blood pressure, and so opposing ventricular action. Palpitation here indicates that the obstruction offered to the blood flow is more than the heart can comfortably overcome. Such is the palpitation common in Bright's disease, even when there is fair hypertrophy, more often however found in women with combined hypertrophy and dilatation, than in men with pure hypertrophy, until indeed that hypertrophy is yielding before structural decay. (Niemeyer, Practical Medicine, vol ii., p. 322.) Such is the palpitation of hysteria, where there is also spasm of the arteriole; here palpitation is not evoked by effort, but manifests itself only during the fit. The heart may be perfectly sound, and competent to meet ordinary demands upon it. But 
the spasm of the arterioles readily calls out palpitation, and these are the cases benefited by the administration of a depressant. The virtue of the drug lies not, however, in allaying the heart's efforts, but in its action upon the contracted peripheral vessels. Dilating them, and so lowering the blood-pressure, it thus removes the difficulty, and then the palpitation passes away; just as we have seen Dr. Brunton relieve angina by nitrite of amyl.

In this way, colchicum and potash relieve violent action of the heart, which cannot be designated palpitation; a condition often found in granular kidney. Potash, like colchicum, is a vascular depressant and Botkin of St. Petersburgh, in his work on Discases of the Heart (I87o, French translation), discusses its action at some length. But it is probable that these agents are useful, not so much by the direct depressant action which they possess upon the circulation, as by their indirect action in eliminating the histolytic products in the blood, upon whose presence in excess this condition depends. According to Ludwig and Traube, this excess of waste products stimulates the vaso-motor centre, and inducesspasm of the arterioles and high arterial tension; their removal, then, by these agents, reduces the spasm, and with it the demand upon the heart. Practically I have found potash and colchicum more efficacious in the treatment of palpitation in Bright's disease, with out the addition of digitalis, than digitalis alone without the other (The Heart and its Diseases: with their Treatment, 1872); nor is it difficult to see that it should be so. The combination of these remedies is the treatment par excellence of this condition.

If this consideration of the mode of action of the depressants of the circulation aids, however little, in casting into something like order this class of remedial agents, and in rescuing them from their chaotic condition, the time spent by me in preparing this paper, and taken up by you in listening to it, may not have been entirely wasted or consumed in vain. It might have been desirable to have contrasted with the agents enumerated here, the apyretic remedies so much employed in Germany, as digitalis, quinine, etc., which act by stimulating the vasomotor centre, and producing general contraction of the peripheral vessels, and a rising blood-pressure, with a falling temperature (Ackermann, Berliner Klin. Wochenschrift, 1872), had time and space permitted.*

\section{THERAPEUTIC MEMORANDA.}

\section{AN IMPROVED PLUG FOR EPISTAXIS.}

UNDER the above heading, I read in this day's JOURNAL a description of a new contrivance by Dr. H. C. Rose which he brings forward with a view towards superseding the old and commonly adopted method of nasal plugging in the more severe cases of epistaxis occasionally encountered. Doubtless, it will not be uninteresting either to Dr. Rose himself or our brother members of the Association, to become aware, should they not have been previously informed, that India-rubber plugs, on a similar principle, have already been invented by my friend, Mr. Nugent, F.R.C.S., of Monkstown, and can be procured of three different sizes (Nos. I, 2, and 3, respectively), at Messrs. Weiss' of the Strand, by whom they have been devised, according to the instructions of Mr. Nugent. At the last meeting of the Drogheda Medical Society, of which I am Secretary, I exhibited, on behalf of the inventor, one of these plugs, and read extracts from a letter of his, wherein he describes the perfect efficiency of the appliance in cases in which he had recourse to it. The instrument to which I refer, is a simple India-rubber tube with a dumb-bell shaped dilatation about two inches in length at one of its extremities, which, when distended with air or filled with water, is meant to fill the nasal cavity and completely plug the fossæe posteriorly and anteriorly. There is an exterior pocket at the distal extremity of the plug, to accommodate the end of a gum-elastic catheter by means of which it is meant to be introduced. On the whole, the apparatus may be regarded as a Barnes's dilator adapted to the nose, though Mr. Nugent asserts that the former never occurred to his mind when the idea of nasal plugging by dilatation first struck him. I think I remember reading some such suggestion in the Lancot a few months ago, but whose it was, or to what exact purport, I do not remember. There is no stopcock attached to Mr. Nugent's plug, but one could easily be adjusted to it. A piece of worsted secures it equally well. I understand, wherever the contrivance has been made use of, it has been facile of introduction, and efficient as regards fulfilment of intention, and,

* It must not be supposed that, in classing the above mentioned agents as depressants of the circulation, there is any intention to insinuate the suggestion that these remedial agents possess no other action; or that mercury and opium act only upon and through the circulation. They are grouped here in so far as they are vascular depressants, and therefore coming under that heading, without reference to any other action they possess. should it continue to prove so upon a more extended trial, both operator and patient will be saved that most disagreeable operation-obturatio narium - with a Bellocq's sound.

For my own part, I may add that I seldom or never have to plug at all, as I find a strong solution of the persulphate of iron, or iron alum, in almost every case finally efficacious as a styptic.

Francis E. Clarke, M.A., M.D.Dub., L.K.Q.C.P., etc. Drogheda.

\section{TREATMENT OF ONYCHIA MALIGNA WITH NITRATE OF LEAD.}

HAVING seen in the JoURNAL an abstract of Mr. Mac Cormac's paper, read at the British Medical Association, on Peruzzi's treatment of onychia maligna with nitrate of lead, I used the drug in the next case I met with. The disease, which affected the thumb of a girl aged 9 , was of a severe form, and of many months' duration. 'The child's mother said she had taken her to various surgeons, and that none had done her any good. She was so discouraged by these failures that she believed the thumb would never get well, and said she would give any one five pounds who would cure it. I ordered the powdered nitrate to be dusted upon the onychia every night and morning, and gave the child cod-liver oil and steel wine. On seeing her again at the end of a fortnight, I found that she was cured. The fragments of the old nail had disappeared; the ulcer was completely healed; the end of the thumb was nearly restored to its proper size ; and the skin, which at first was of a deep dusky-red colour, was now almost natural. The first application of the nitrate increased the pain for about a quarter of an hour, but after this. scarcely any pain was felt. Before the lead was used, the pain had been very severe.

This case gives all the experience I have yet had of the treatment of onychia maligna with nitrate of lead. As far as it goes, it agrees precisely with those referred to by Mr. Mac Cormac, as having been treated by Dr. Johnstone Scott in Belfast. I may add, that the disease is clearly much more common and much more severe in Ireland than in London. Not more than five or six cases are seen in a year at the Children's Hospital. In the majority of these it is in the fingers, and not in the toes. Although arsenical lotions will very often quickly cure the affections, some cases have been extremely obstinate and troublesome; and the discovery of this new remedy will be most welcome, if it prove, as there seems good reason to believe, both rapid and certain in its effect. HownRd MARSH, F.R.C.S., Assistant-Surgeon to St. Bartholomew's Hospital, and to the Hospital for Sick Children.

\section{CLINICAL MEMORANDA.}

\section{PRIMARY VACCINATION DURING PERIOD OF INCUBA.}

\section{TION OF SMALL-POX : CONFINEMENT DURING} ATTACK OF THAT DISEASE: RECOVERY.

ON the morning of November I9th last, I was called to see John Johnson, seaman, in this town, whom I found to be suffering from a severe attack of small-pox. On learning that his wife, who had been in attendance since the commencement of the disease, had never been vaccinated, I thought it right immediately to perform that operation on her, notwithstanding the circumstance that she was within a few days of her confinement. Both husband and wife were immediately removed to the Small-pox Hospital ; and, two days afterwards - i.e., as soon as arrangements could possibly be made-Mrs. Johnson was removed to a separate part of the building. Vaccination was as successful as could have been desired, both vesicles attaining maturity at the week's end-viz., on the 26 th November. At this time the poor woman was enduring great mental distress, for the disease in her husband, who had never been vaccinated, assumed a semi-confluent form, and proved fatal on the morning of the 27 th. That same day, Mrs. Johnson was seized with febrile symptoms, which I at that time attributed to vaccination. On the morning of the 29th, labour-pains set in, and that evening she was delivered of a living female child. Next night, the eruption of small-pox appeared on the mother.

Of this attack, there is nothing special to remark further than that it proved decidedly a case of unprotected variola-i.e., it assumed none of the distinguishing features of the variola which occurs in a subject previously vaccinated. The eruption was discrete and remarkably well developed ; and there occurred a decided secondary fever, accompanied by violent delirium, and followed by considerable prostration, during which stimulants were had recourse to. Convalescence, which may be said to date from the 9th December-the twelfth or thirteenth day of the disease-has progressed most satisfactorily. 